\title{
Sequential quadratic programming particle swarm optimization for wind power system operations considering emissions
}

\author{
Yang ZHANG (ه), Fang YAO, Herbert Ho-Ching IU, \\ Tyrone FERNANDO, Kit Po WONG
}

\begin{abstract}
In this paper, a computation framework for addressing combined economic and emission dispatch (CEED) problem with valve-point effects as well as stochastic wind power considering unit commitment (UC) using a hybrid approach connecting sequential quadratic programming (SQP) and particle swarm optimization (PSO) is proposed. The CEED problem aims to minimize the scheduling cost and greenhouse gases (GHGs) emission cost. Here the GHGs include carbon dioxide $\left(\mathrm{CO}_{2}\right)$, nitrogen dioxide $\left(\mathrm{NO}_{2}\right)$, and sulphur oxides $\left(\mathrm{SO}_{\mathrm{x}}\right)$. A dispatch model including both thermal generators and wind farms is developed. The probability of stochastic wind power based on the Weibull distribution is included in the CEED model. The model is tested on a standard system involving six thermal units and two wind farms. A set of numerical case studies are reported. The performance of the hybrid computational method is validated by comparing with other solvers on the test system.
\end{abstract}

Keywords Combined economic and emission dispatch, Unit commitment, Particle swarm optimization, Sequential quadratic programming, Weibull distribution, Wind power

\section{Introduction}

Power system generation scheduling problem can be divided into two sub-problems, unit commitment (UC) and economic dispatch (ED). ED is an important task in the

Received: 23 July 2013/Accepted: 10 October 2013/Published online: 5 November 2013

(C) The Author(s) 2013. This article is published with open access at Springerlink.com

Y. ZHANG, F. YAO, H. H.-C. IU, T. FERNANDO,

K. P. WONG, The University of Western Australia, Perth, WA, Australia

(凹) e-mail: 20738164@student.uwa.edu.au power system operation, which aims to allocate power generation match load demand at minimal possible cost while satisfying all the units and system constraints [1-3]. Suitable improvements in the unit outputs scheduling can contribute to significant cost savings.

Nowadays, with the awareness of environmental pollution contributed by the combustion of fossil fuels, building a low-carbon world has attracted widespread attentions. Many countries are trying to exploit clean energy in order to mitigate the greenhouse effects. The primary source of greenhouse gases (GHGs) is the combustion of fossil fuels. Coal, oil, and gas are the three major types of regular fuels, which produce emissions represented by GHGs, such as $\mathrm{CO}_{2}, \mathrm{NO}_{2}$, and SOx. In order to reduce the GHGs emissions, the combined economic emission dispatch (CEED) considering with UC was proposed, which can take account of fuel cost and emission tax together. Because the amount of emission from fossil-based thermal generators depends on the amount of generated power, therefore the emission cost increase leads to reduced overall power generated by thermal units, which in turn lowers emissions. Moreover, the natural economic forces will also help to catalyse the move to greater energy efficiency and use of renewable sources. Wind energy is among the major contributors to an overall reduction in GHGs emissions. Dispatch strategies normally can provide quick solutions to improve the current situation of system operation and reduce carbon emissions dramatically. On the other hand, exploiting renewable energy is another effective way to mitigate energy source deficiency, control GHGs emissions, and achieve smart grid vision [4-6]. Wind power being one of the most appealing renewable energy resources has gained widespread concerns during the last decades. Along with the introduction of various emission reduction schemes, increasing number of wind turbines have been installed around the world [7]. However, due to the intermittent and 


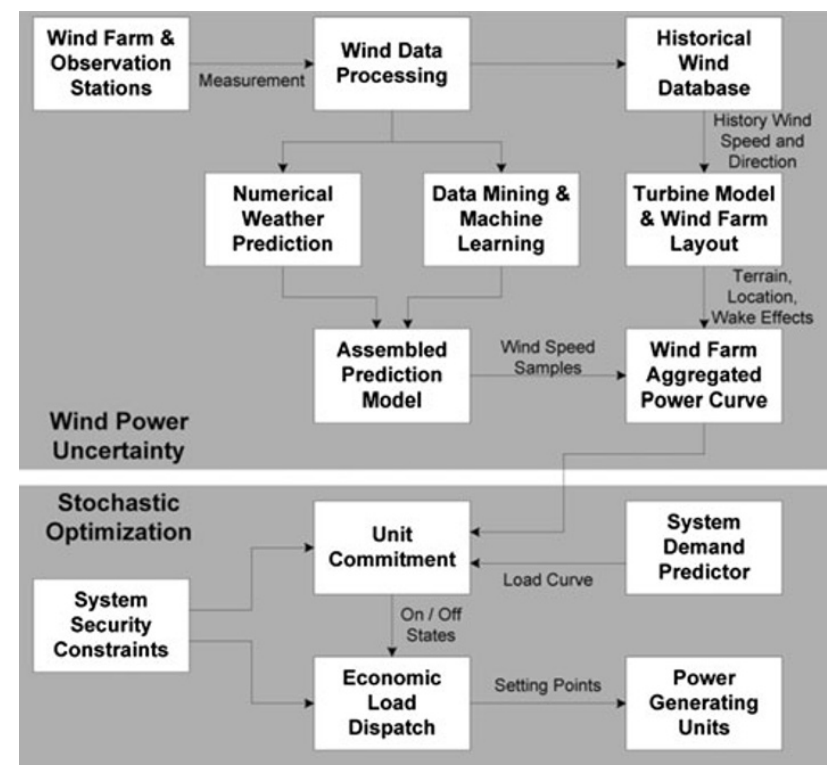

Fig. 1 Computational framework considering wind power uncertainties

stochastic characteristics of wind resource, wind power brings great challenges to power system economic dispatch problems. One of the major challenges is how to effectively accommodate the wind forecasting errors. Because variations of wind speed directly influence the power output of wind farms, which then causes difficulties in estimating suitable system reserve margin to ensure secure and reliable system operations. As a result, high penetration of wind power also causes high potential risks and more difficulties in power system operation. Although wind speed is difficult to forecast by single predictor, composite forecast model can statistically produce an optimal forecast by computing prediction results from a number of different methods. The fundamental concept is that if the errors in the forecasts produced by different methods are unbiased and have a low degree of correlation with each other, the random errors from the individual forecasts will tend to offset each other, with the result that a composite of the forecasts will have lower errors than any individual forecast. Moreover, huge number of publications has indicated that wind speed follows Weibull distribution approximately [8]. In order to assist with management of the uncertainties of wind forecasts, extensive researches have been conducted to develop kinds of probabilistic optimization strategies $[9,10]$. In this paper, a schematic representation of computational framework contains wind power forecast and stochastic unit commitment/economic dispatch, which is adopted from [38], is shown in Fig. 1.

In order to accommodate the revised dispatch strategy, more efficient solvers are needed. Different heuristic techniques have been developed to solve the classical ED problems with constraints, to namely simulated annealing (SA) [11], genetic algorithm (GA) [12], evolutionary programming (EP) [13, 14], tabu search (TS) [15], pattern search (PS) [16], particle swarm optimization (PSO) [17, 18], as well as differential evolution (DE) [19, 20]. Based on our experience, when compared with other approaches, the PSO is computationally inexpensive in terms of memory and speed. However, these heuristic methods do not always guarantee discovering globally optimal solutions in finite time, especially when being applied into large-scale optimization problems. Therefore, more sophisticated computational tools are required. Recently, hybrid optimization techniques which combine different approaches receive widespread concerns. In [21], the authors presented a hybrid EP and sequential quadratic programming (SQP) for solving the ED problem with nonsmooth fuel cost function. A hybrid self-tuning DE was proposed to solve the ED problem with kinds of constraints in [22]. In [23], a hybrid approach combining DE with biogeography-based optimization (DE/BBO) was developed to address both convex and non-convex ED problem. These hybrid optimization methods were found to be more effective and accurate. SQP is one of best nonlinear-programming method for constrained optimization. SQP-PSO technique is an effective nonlinear-programming method over a large number of test problems in terms of accuracy, efficiency and percentage of successful solutions.

In this paper, a CEED model incorporating wind power to minimize the total cost is proposed. Because of the stochastic nature of wind speed, wind power output is not deterministic. As a sequence, the probability distribution of wind speed must be taken into account in the CEED model.

In our CEED model, wind power is described as the three-parameter Weibull distribution. As ED problem in consideration of emission issue, there are some works reducing the $\mathrm{NO}_{2}$, as well as $\mathrm{SO}_{2}$, however, there are few papers on CEED in consideration of the $\mathrm{CO}_{2}$ emission. In this paper, the reduction of $\mathrm{CO}_{2}$ emission is one of the main concerns in the CEED model. In terms of the problem solver, we present a hybrid technique which combines SQP and PSO together. In the proposed algorithm, SQP is firstly used to solve the CEED problem without considering the valve-point effects, and then based on the obtained initial solution and boundaries PSO is employed to solve the CEED problem with non-smooth fuel cost function.

The rest of this paper is organized as follows. Section 2 introduces the probability of wind power. Section 3 describes the mathematical formulation of CEED considering UC problem with stochastic wind power. The basic concepts of SQP and PSO are introduced in Section 4, and the hybrid algorithm is also summarized in this section. Section 5 presents the numerical case studies solving the 


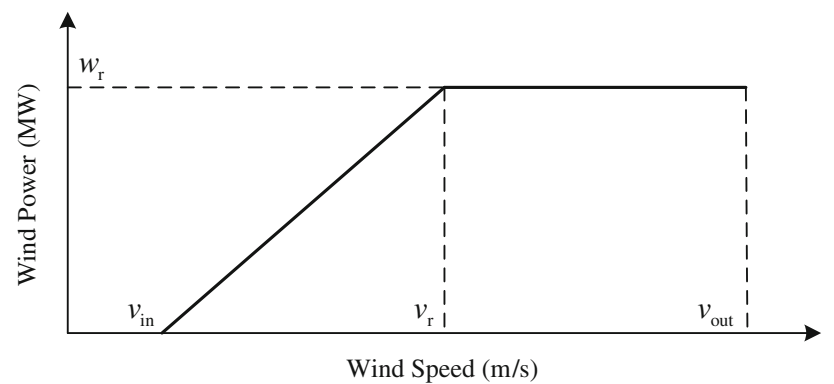

Fig. 2 Simplified wind turbine power curve

ED and CEED problems with and without wind power. Remarks and conclusions are given in Section 6.

\section{Probabilistic modeling of wind power for edmodeling}

Wind power, one of the most appealing renewable energy sources, has been widely developed in the recent years. Wind power energy has lots of advantages such as no pollution, relatively low capital cost involved, and the short gestation period required. However, the wind resource changes with locations and climates resulting in high uncertainties in the produced energy. The total power available from a wind turbine is equal to the product of the mass flow rate of the wind $m_{\mathrm{W}}$, and $V^{2} / 2$. Assuming constant area or ducted flow, the continuity equation states that $m_{\mathrm{W}}=\rho A V$, where $\rho$ is the density of the air in $\mathrm{kg} / \mathrm{m}^{3}, A$ is the blades area in $\mathrm{m}^{2}$, and $V$ is the velocity in $\mathrm{m} / \mathrm{s}$. Thus, the total wind power becomes $P_{\mathrm{W}}=\left(m_{\mathrm{W}} V^{2}\right) / 2=\left(\rho A V^{3}\right) / 2$ (MW). In this equation, the wind speed $V$ is a random variable. Ignoring minor nonlinearities, the function relation between a given wind speed and power output can be described in Fig. 2.

In the above figure, $w(\mathrm{MW})$ is the wind energy conversion systems (WECS) output power; $w_{\mathrm{r}}(\mathrm{MW})$ is the WECS output rated power; $v_{\text {in }}(\mathrm{m} / \mathrm{s}), v_{\mathrm{r}}(\mathrm{m} / \mathrm{s}), v_{\text {out }}(\mathrm{m} / \mathrm{s})$ is the WECS cut-in speed, rated speed, and cut-out speed, respectively. Figure 1 shows that there is no power generated at wind speeds below $v_{\text {in }}$ or above $v_{\text {out }}$; at wind speeds between $v_{\mathrm{r}}$ and $v_{\text {out }}$, the output is equal to the rated power of the generator; at wind speeds between cut-in wind speed and rated wind speed, the output is a linear function power.

Therefore, the wind power output can be described as,

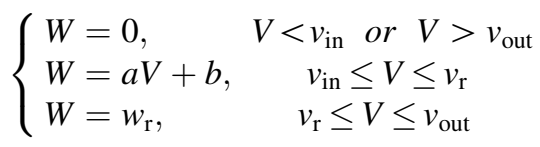

where $a=\frac{w_{\mathrm{r}}}{v_{\mathrm{r}}-v_{\text {in }}}, \quad b=-\frac{v_{\text {in }} w_{\mathrm{r}}}{v_{\mathrm{r}}-v_{\text {in }}}$.

Weibull distribution is the most popular density function that can be used to describe wind speed frequency curve
[24-26]. An extensive review of various probability density functions of wind speed was provided in [26], and comparisons were made. The results indicated that the twoparameter Weibull distribution is the widely accepted model. Using two-parameter Weibull distribution, cumulative distribution function (CDF) and probability density function (pdf) of wind speed are

$F_{V}(v)=1-\exp \left[-\left(\frac{v}{c}\right)^{k}\right], \quad(v \geq 0)$

$f_{V}(v)=\frac{k}{c}\left(\frac{v}{c}\right)^{k-1} \exp \left[-\left(\frac{v}{c}\right)^{k}\right]$

where $k>0$ is the shape parameter, $c>0$ is the scale parameter.

According to (1), three portions of WECS power output can be analysed and the corresponding probabilities (CDF or pdf) can be calculated.

(i) For $V<v_{\text {in }}$ or $V>v_{\text {out }}$,

$$
\begin{aligned}
P(W=0) & =P\left(V<v_{\text {in }}\right)+P\left(V>v_{\text {out }}\right) \\
& =F_{V}\left(v_{\text {in }}\right)+\left[1-F_{V}\left(v_{\text {out }}\right)\right] \\
& =1-\exp \left[-\left(\frac{v_{\text {in }}}{c}\right)^{k}\right]+\exp \left[-\left(\frac{v_{\text {out }}}{c}\right)^{k}\right]
\end{aligned}
$$

(ii) For $v_{\text {in }} \leq V \leq v_{\mathrm{r}}, \quad W=a V+b=\frac{\left(V-v_{\text {in }}\right) w_{\mathrm{r}}}{v_{\mathrm{r}}-v_{\text {in }}}$, depending on the definition of cumulative distribution function (CDF), the CDF of WECS output power can be described as,

$$
\begin{aligned}
F_{W}(w) & =P\{W \leq w\}=P\left\{W=\frac{\left(V-v_{\text {in }}\right) w_{\mathrm{r}}}{v_{\mathrm{r}}-v_{\text {in }}} \leq w\right\} \\
& =P\left\{V \leq \frac{\left(v_{\mathrm{r}}-v_{\text {in }}\right) w}{w_{\mathrm{r}}}+v_{\text {in }}\right\}=F_{V}\left\{\frac{\left(v_{\mathrm{r}}-v_{\text {in }}\right) w}{w_{\mathrm{r}}}+v_{\text {in }}\right\}
\end{aligned}
$$

We can obtain the pdf of $W$ by differentiating with respect to $w$. The chain rule for derivatives can be used, $\frac{\mathrm{d} F}{\mathrm{~d} w}=\frac{\mathrm{d} F}{\mathrm{~d} u} \frac{\mathrm{d} u}{\mathrm{~d} w}$, where $u$ is the argument of $F$, $u=\left\{\frac{\left(v_{\mathrm{r}}-v_{\text {in }}\right) w}{w_{\mathrm{r}}}+v_{\text {in }}\right\}$, and then we obtain

$$
\begin{aligned}
f_{W}(w)= & \frac{k\left(v_{\mathrm{r}}-v_{\text {in }}\right)}{c w_{\mathrm{r}}} \cdot\left[\frac{\frac{\left(v_{\mathrm{r}}-v_{\text {in }}\right) w}{w_{\mathrm{r}}}+v_{\text {in }}}{c}\right]^{k-1} . \\
& \exp \left[-\left(\frac{\frac{\left(v_{\mathrm{r}}-v_{\text {in }}\right) w}{w_{\mathrm{r}}}+v_{\text {in }}}{c}\right)\right]^{k}
\end{aligned}
$$

(iii) For $v_{\mathrm{r}} \leq V \leq v_{\text {out }}$,

$$
\begin{aligned}
P\left(W=w_{\mathrm{r}}\right) & =P\left(v_{\mathrm{r}} \leq V \leq v_{\text {out }}\right) \\
& =F_{V}\left(v_{\text {out }}\right)-F_{V}\left(v_{\mathrm{r}}\right) \\
& =\exp \left[-\left(\frac{v_{\mathrm{r}}}{c}\right)^{k}\right]-\exp \left[-\left(\frac{v_{\text {out }}}{c}\right)^{k}\right]
\end{aligned}
$$




\section{Mathematical formulation of CEED problem with wind power}

This section describes the problem formulation of the proposed CEED considering UC model including wind power. The model aims at minimizing the total operation costs (including fuel cost, wind farm cost) and emission cost while satisfying the given constraints. In [27], an economic dispatch (ED) model incorporating wind power is developed. In order to accurately characterize the uncertainty in the availability of wind energy, penalty costs functions for both underestimation and overestimation cases were added. Inspired by the practical application, a similar CEED model are developed with an additional term incorporated to account for government wind farm subsidy. To address the uncertainties in wind power production, wind speed distribution probability functions are applied in formulating the optimization model.

\subsection{Objective function}

The objective function is formulated to minimize the total system operation costs and greenhouse gases $\left(\mathrm{CO}_{2}\right.$ and $\mathrm{NO}_{2}$ ) emission costs. A cost function is obtained based on the ripple curve for more accurate modelling which contains higher order nonlinearity and discontinuity due to the valve point effect [16] and should be refined by a sine function [28]. The overall objective function can be expressed as the sum of these two terms,

Min. $\left(\right.$ Cost $_{1}+$ Cost $\left._{2}\right)$

1) Total system scheduling costs

$$
\begin{aligned}
\operatorname{Cost}_{1}= & \sum_{i=1}^{M} C_{i}\left(p_{i}\right)+\sum_{j=1}^{N} C_{\mathrm{w}, j}\left(w_{j, \mathrm{av}}\right) \\
& +\sum_{j=1}^{N} C_{\mathrm{u}, j}\left(W_{j, \mathrm{av}}-w_{j}\right)+\sum_{j=1}^{N} C_{\mathrm{o}, j}\left(w_{j}-W_{j, \mathrm{av}}\right) \\
& -\sum_{j=1}^{N} C_{\mathrm{s}, j}\left(w_{j, \mathrm{av}}\right) \\
C_{i}\left(p_{i}\right)=a_{i}+ & b_{i} p_{i}+c_{i} p_{i}^{2}+\left|d_{i} \sin \left(e_{i}\left(p_{i, \min }-p_{i}\right)\right)\right|
\end{aligned}
$$

where $M$ is the number of thermal power generators; $N$ the number of wind turbines; $a_{i}, b_{i}, c_{i}$ the cost coefficients of thermal generator $i ; d_{i}, e_{i}$ are valve-point effects coefficients of thermal generator $i$; $C_{i}$ the cost function of thermal generator $i$; $C_{\mathrm{u}, j}$ the cost coefficient for not using all generated wind power due to the underestimation case; $C_{\mathrm{o}, j}$ the cost coefficient for purchasing reserve power from other source due to overestimation case; $C_{\mathrm{s}, j}$ the government subsidy parameter of turbine $j ; C_{\mathrm{w}, j}$ the cost coefficient of wind turbine $j ; p_{i}$ the actual power generated by thermal generator $i ; w_{j}$ the predicted wind power generated by turbine $j ; W_{j \text {,av }}$ the actual wind power generated by wind turbine $j ; C_{i}\left(p_{i}\right)$ the fuel cost function of thermal generator $i ; C_{\mathrm{w}, j}\left(w_{j, \text { av }}\right)$ the wind power cost of the wind farm.

If the wind farm is owned by the system operator, this term may not exist. In this paper, the wind farm is assumed to be owned by the operator, so this cost is equal to zero. The underestimation cost $C_{\mathrm{u}, j}\left(W_{j, \mathrm{av}}-w_{j}\right)$ occurs if the actual generated wind power is more than the predicted, thus the system operator should compensate for the surplus wind power cost. On the other hand, if the actual wind power is less the predicted scheduling power, the operator needs to purchase from an alternate source and pay the overestimation cost $C_{\mathrm{o}, j}\left(w_{j}-W_{j, \text { av }}\right)$. The last term in the Eq. (9) is the wind power subsidy $\operatorname{cost} C_{\mathrm{s}, j}\left(w_{j, \mathrm{av}}\right)$. As one of the renewable energy subsidy projects, wind farm in many countries receive a largely covert subsidy. An excellent example is the Renewable Obligation (RO) in UK. The RO is designed to encourage generation of electricity from eligible renewable sources in the UK [29]. In this paper, the wind farm was assumed to receive a fix cost subsidy for generating every MW wind power.

According to [29], the cost of underestimation will be assumed as follow,

$$
\begin{array}{r}
C_{\mathrm{u}, j}\left(W_{j, \mathrm{av}}-w_{j}\right)=C_{\mathrm{u}, j} \int_{w_{j}}^{w_{\mathrm{r}, j}}\left(w-w_{j}\right) f_{W}(w) d w \\
=C_{\mathrm{u}, j}\left[\int_{w_{j}}^{w_{\mathrm{r}, j}} w f_{W}(w) d w-w_{j} \int_{w_{j}}^{w_{\mathrm{r}, j}} f_{W}(w) d w\right]
\end{array}
$$

where $w_{\mathrm{r}, j}$ is the rated wind power from wind turbine $j$.

In terms of overestimation case, the cost equation will be in the similar manner,

$$
\begin{array}{r}
C_{\mathrm{o}, j}\left(w_{j}-W_{j, \mathrm{av}}\right)=C_{\mathrm{o}, j} \int_{0}^{w_{j}}\left(w_{j}-w\right) f_{W}(w) d w \\
=C_{\mathrm{o}, j}\left[w_{j} \int_{0}^{w_{j}} f_{W}(w) d w-\int_{0}^{w_{j}} w f_{W}(w) d w\right]
\end{array}
$$

Equations (11) and (12) can be solved through the wind power probability (4)-(7).

2) Greenhouse gases (GHGs) emission costs

Cost $_{2}=\sum_{i=1}^{M} F_{\mathrm{GHG}, i}\left(p_{i}\right)$

where $F_{\mathrm{GHG}, i}\left(p_{i}\right)$ is the emission cost of thermal unit $i$.

$$
\begin{aligned}
& F_{\mathrm{GHG}, i}\left(p_{i}\right)=h \cdot \operatorname{EM}_{i}\left(p_{i}\right) \\
& E M_{i}\left(p_{i}\right)=e f_{i}\left(f_{i}+g_{i} p_{i}+h_{i} p_{i}^{2}\right)
\end{aligned}
$$

where $E M_{i}\left(p_{i}\right)$ is the GHGs emissions of thermal generator $i$; $e f_{i}$ the fuel emission factor of GHGs for thermal generator $i ; f_{i}, g_{i}, h_{i}$ the fuel consumption coefficients of thermal 
unit; $h$ is the given GHGs emissions price which is determined by regulations and markets. GHGs are $\mathrm{CO}_{2}$ and $\mathrm{NO}_{2}$ in this paper

Equation (13) represents the fuel cost function of thermal generators. Equation (14) expresses the GHGs emission cost function.

\subsection{System constraints}

$p_{i, \min } \leq p_{i} \leq p_{i, \max }$

$0 \leq w_{j} \leq w_{\mathrm{r}, j}$

$\sum_{i=1}^{M} p_{i}+\sum_{j=1}^{N} w_{j}=p_{\mathrm{d}}+p_{\text {loss }}$

where $p_{\mathrm{d}}$ is total system loads; and $p_{\text {loss }}$ is total transmission losses.

Inequality constraint (16) defines the limitations of thermal units output from the lower to the upper bound. And constraint (17) shows the wind power output limitations. Equation (18) gives the power balance between generations and loads including the transmission losses.

\section{Hybrid optimization algorithm}

In this section, a hybrid optimization algorithm is presented, which combines SQP and PSO together.

\subsection{Sequential quadratic programming (SQP)}

Since its popularization in the late 1970s, SQP has arguably become the most successful approaches for solving nonlinearly constrained optimization problems [30]. Backed by a mature and solid theoretical background, SQP has been developed and used to solve a remarkably large number of practical problems. The basic principle of sequential approximations is to replace the given problem by a sequence of quadratic sub-problems that are easier to solve [31, 32]. Consider the application of the SQP methodology to nonlinear optimization problems,

Min. $f(x)$

s.t. $\left\{\begin{array}{l}h(x)=0 \\ g(x) \leq 0\end{array}\right.$

The Lagrangian of this problem can be written as,

$L(x, \lambda . \mu)=f(x)+\lambda h(x)+\mu^{T} g(x)$

where $\lambda$ and $\mu$ are vectors of multipliers. SQP is an iterative procedure which models the problem for a given iterate $x^{k}$ by a quadratic programming sub-problem, solves that quadratic programming sub-problem, and then uses the solution to construct a new iterate $x^{k+1}$.
The sub-problem can be constructed by linearizing the constraints of around $x^{k}$, and it can be written as,

Min $\nabla f\left(x^{k}\right)\left(x-x^{k}\right)+\frac{1}{2}\left(x-x^{k}\right)^{T} H f\left(x^{k}\right)\left(x-x^{k}\right)$

s.t. $\left\{\begin{aligned} h\left(x^{k}\right)+\nabla h\left(x^{k}\right)\left(x-x^{k}\right) & =0 \\ g\left(x^{k}\right)+\nabla g\left(x^{k}\right)\left(x-x^{k}\right) & \leq 0\end{aligned}\right.$

We need to update the estimates of the multipliers, and define the corresponding search directions, and then choose a step size and define the next iterate.

\subsection{Particle swarm optimization}

PSO is a global search technique originally introduced by Kennedy and Eberhart [33]. It simulates the social evolvement knowledge, probing the optimum by evolving the population which may include candidate solutions. In the classical PSO, each individual is treated as a particle in the space, with position and velocity vectors. The algorithm maintains a swarm of particles, where each particle represents a potential solution to the objective problem. For a given $n$-dimensional problem, the position and velocity vectors of a particle in the PSO can be represented as

$\left\{\begin{array}{l}x_{j}(t)=\left[x_{j, 1}(t), x_{j, 2}(t) \ldots, x_{j, n}(t)\right] \\ v_{j}(t)=\left[v_{j, 1}(t), v_{j, 2}(t) \ldots, v_{j, n}(t)\right]\end{array}\right.$

The core idea of the classical PSO is the exchange of information among the global best, population best, and current particles, which can be done as follows

$$
\begin{aligned}
v_{j}(t+1)= & \omega \cdot v_{j}(t)+\varphi \cdot r_{1} \cdot\left[p_{\mathrm{pb}}(t)-x_{j}(t)\right] \\
& +\eta \cdot r_{2} \cdot\left[p_{\mathrm{gb}}(t)-x_{j}(t)\right] \\
x_{j}(t+1)= & x_{j}(t)+v_{j}(t+1)
\end{aligned}
$$

where $v_{j}$ is velocity vectors; $\omega$ the inertia weight; $p_{\mathrm{pb}}$ the local best particle; and $p_{\mathrm{gb}}$ is global best particle, $\varphi=1.65$, $\eta=1.81$.

\subsection{Composite computation approach}

The procedures of the proposed hybrid algorithm are summarized as the follows,

Step-1. Load history wind data, generators and wind turbines settings, emission parameters, and forecast wind power output;

Step-2. Solve the ED and CEED problem without considering valve-point effects incorporating wind power using SQP;

Step-3. Calculate the updated constraints using (24) [34], and randomly generate initial population around the solution obtained from SQP for PSO; 


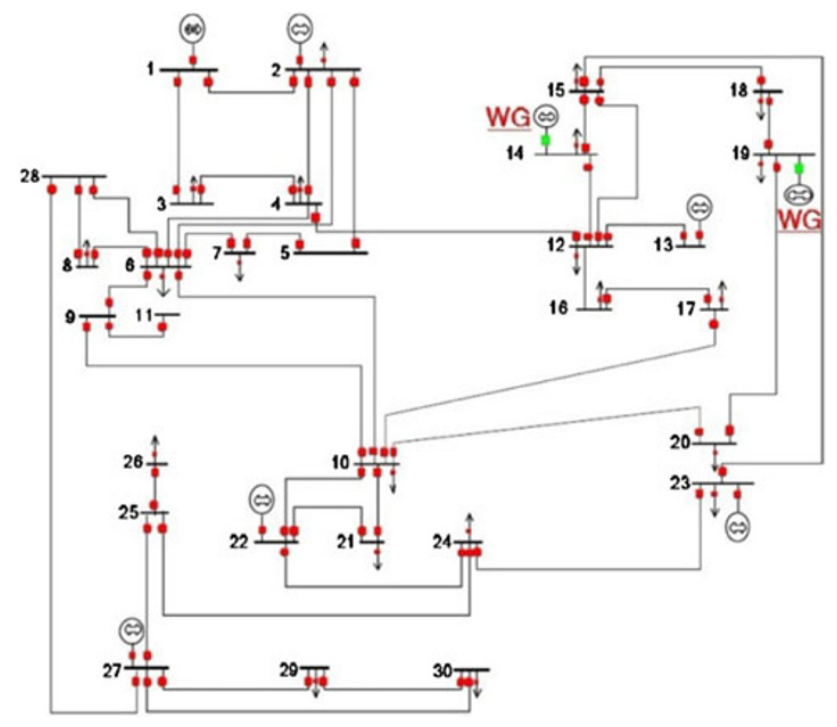

Fig. 3 Modified IEEE 30-bus system

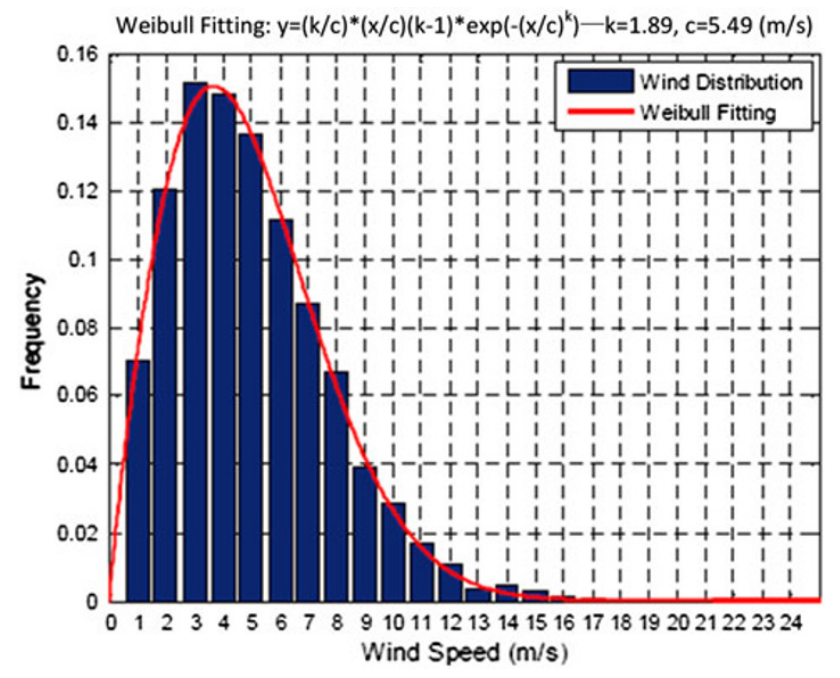

Fig.4 Wind speed distribution and Weibull fitting

$\left\{\begin{array}{l}p_{i, \min }=\max \left(\left[p_{i}-\beta_{i}\right], p_{i, \min }\right) \\ p_{i, \max }=\min \left(\left[p_{i}-\beta_{i}\right], p_{i, \max }\right) \\ \beta_{i}=\pi /(1+\gamma) e_{i}\end{array}\right.$

Step-4. Solve the ED and CEED problem with valve-point effects incorporating wind power using PSO;

Step-5. Save and output final solution. Application of this approach in ED and CEED problem incorporating wind power are presented in the following section.

\section{Case studies}

The QPSO is implemented on a modified IEEE 30-bus system. The benchmark system consists of 6 thermal
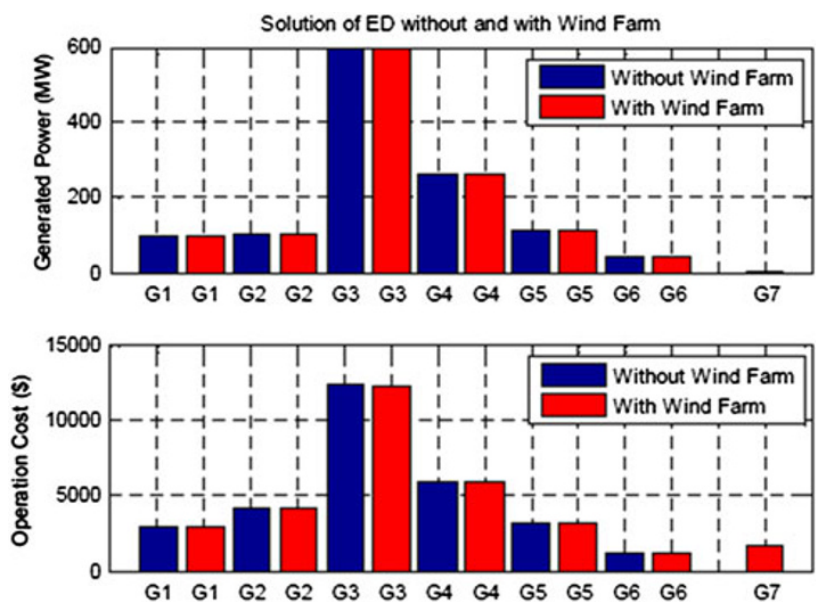

Fig.5 Solutions of ED models without and with wind farm

Table 1 Wind power factors

\begin{tabular}{lllllllllll}
\hline$c$ & $k$ & $\theta$ & $v_{\text {in }}$ & $v_{\text {out }}$ & $v_{\mathrm{r}}$ & $w_{\mathrm{r}}$ & $C_{\mathrm{w}, j}$ & $C_{\mathrm{u}, j}$ & $C_{\mathrm{o}, j}$ & $C_{\mathrm{s}, j}$ \\
\hline 5.5 & 1.89 & 0 & 4 & 25 & 16 & 3 & 0 & 60 & 20 & 10 \\
\hline
\end{tabular}

generators, 2 wind farms, 41 branches, and 21 loads. These thermal generators include 3 coal-fired units, 2 gas-fired units, and 1 oil-fired unit. The test system is shown in Fig. 3 [35].

In the case study part, the CEED model with wind power was evaluated using the historical wind speed dataset from a wind observation station in Tasmania, Australia. The data was provided by the Australian Bureau of Meteorology [36]. Here we assume that the wind speed data from a large wind farm and use the data to estimate the generated wind power. The wind speed distribution frequency and the corresponding Weibull distribution parameters are presented in Fig. 4.

The Vestas V90 3.0 MW wind turbine is selected for the case studies. It is a pitch regulated upwind wind turbine with active yawing and a three-blade rotor. It has a rotor diameter of $90 \mathrm{~m}$ with a generator rated at $3.0 \mathrm{MW}$. The Vestas V90 3.0 MW is widely used in the wind plants in Australia and has a proven high efficiency. The parameters of the associated Weibull distribution factor and wind farm parameters can be calculated from the wind speed data and are given in Table 1.

The wind farm totally consists of 100 Vestas V90 3.0 MW wind turbines located in a coherent geographic area. The predicted power output for each wind turbine is denoted as $w_{j}$ and is $15 \%$ of the rated power, which is $0.45 \mathrm{MW}$. Depended on the actual generated wind power, the extra cost will be determined by overestimation case or underestimation case. According, the maximum capacity of the system under investigation is 2,030 and 2,330 MW incorporating with wind power. The fuel cost coefficients, 
Table 2 Fuel cost coefficients

\begin{tabular}{llrlrl}
\hline Unit & \multicolumn{5}{l}{ Fuel cost coefficients } \\
\cline { 2 - 6 } & $a_{i}$ & $b_{i}$ & $c_{i}$ & $d_{i}$ & $e_{i}$ \\
\hline G1 (Coal) & 2,000 & 10 & 0.002 & 200 & 0.084 \\
G2 (Coal) & 2,500 & 15 & 0.0025 & 300 & 0.035 \\
G3 (Coal) & 6,000 & 9 & 0.0018 & 400 & 0.042 \\
G4 (Gas) & 923.4 & 18 & 0.00315 & 150 & 0.063 \\
G5 (Gas) & 950 & 20 & 0.0032 & 100 & 0.084 \\
G6 (Oil) & 124.8 & 23.4 & 0.003432 & 80 & 0.098
\end{tabular}

The coefficients of $a_{i}, b_{i}, c_{i}$ and $e_{i}$ are in $\$, \$ / \mathrm{MW}$ and $\$ / \mathrm{MW}^{2}$, and \$MW

Table 3 Fuel consumption coefficients and generator limits

\begin{tabular}{|c|c|c|c|c|c|}
\hline \multirow[t]{2}{*}{ Unit } & \multicolumn{3}{|c|}{ Fuel consumption coefficients } & \multirow[t]{2}{*}{$P_{\min }$} & \multirow[t]{2}{*}{$P_{\max }$} \\
\hline & $f_{i}$ & $g_{i}$ & $h_{i}$ & & \\
\hline G1 (Coal) & 40 & 0.2 & 0.00004 & 20 & 110 \\
\hline G2 (Coal) & 50 & 0.3 & 0.00005 & 20 & 100 \\
\hline G3 (Coal) & 80 & 0.12 & 0.000024 & 120 & 600 \\
\hline G4 (Gas) & $2,462.4$ & 48 & 0.0084 & 110 & 520 \\
\hline G5 (Gas) & 2,500 & 50 & 0.009 & 110 & 500 \\
\hline G6 (Oil) & 1.248 & 0.234 & $3.43 e-05$ & 40 & 200 \\
\hline G7 (Wind) & 0 & 0 & 0 & 0 & 300 \\
\hline
\end{tabular}

The coefficients of $f_{i}, g_{i}$, and $h_{i}$ are in $t, t / \mathrm{MW}$ and $t / \mathrm{MW}^{2}$ for coal/oil units. The coefficients of $f_{i}, g_{i}$, and $h_{i}$ are in $\mathrm{m}^{3}, \mathrm{~m}^{3} / \mathrm{MW}$ and $\mathrm{m}^{3} / \mathrm{MW}^{2}$ for gas unit

Table 4 Emission factors of units

\begin{tabular}{llll}
\hline Emission factor & Coal $(\mathrm{kg} / \mathrm{kg})$ & $\mathrm{Gas}\left(\mathrm{kg} / \mathrm{m}^{3}\right)$ & Oil $(\mathrm{kg} / \mathrm{kg})$ \\
\hline $\mathrm{efCO}_{2}$ & 3.1604 & 1.84 & 2.8523 \\
$\mathrm{efNO}_{2}$ & $1.29 \mathrm{e}-03$ & $3.4 \mathrm{e}-04$ & $3.3 \mathrm{e}-04$ \\
\hline
\end{tabular}

generator limits, and fuel consumption coefficients are shown in Tables 2 and 3 [35]. The proposed algorithm is implemented on a test system including 6 thermal generators and 1 large wind farm. There are 3 coal-fired units, 2 gas-fired units, and 1 oil-fired unit in this test system. The wind farm totally consists of 100 Vestas V90 3.0 MW wind turbines located in a coherent geographic area. The predicted power output for each wind turbine is denoted as $w j$ and is $15 \%$ of the rated power, which is $0.45 \mathrm{MW}$. Depended on the actual generated wind power, the extra cost will be determined by overestimation case or underestimation case. The maximum capacity of the system under investigation is 2,030 and 2,330 MW incorporating with wind power. The fuel cost coefficients, generator limits, and fuel consumption coefficients are shown in Tables 2 and 3 [35].
Table 5 Emission prices

\begin{tabular}{lll}
\hline Fuel & $\mathrm{CO}_{2}(\$ / \mathrm{t})$ & $\mathrm{NO}_{2}(\$ / \mathrm{kg})$ \\
\hline Price & 1.5 & 5.0 \\
\hline
\end{tabular}

Table 6 Forecast system demand and wind farm output

\begin{tabular}{lrr}
\hline Case index & Case 1 & Case 2 \\
\hline Demand (MW) & 1,200 & 1,600 \\
G7 & 45 & 45 \\
\hline
\end{tabular}

Table 7 Solution of ELD without wind farm

\begin{tabular}{lcc}
\hline Unit & Power (MW) & Operation cost (\$) \\
\hline G1 (Coal) & 96.9286 & $29,69,047$ \\
G2 (Coal) & 99.4079 & $4,122.16$ \\
G3 (Coal) & 593.5730 & $12,359.45$ \\
G4 (Gas) & 259.1281 & $5,808.68$ \\
G5 (Gas) & 110.6357 & $3,207.22$ \\
G6 (Oil) & 40.3266 & $1,076.58$ \\
Total & $1,200.0000$ & $29,538.56$ \\
Overall cost (\$) & \multicolumn{2}{c}{$29,538.56$} \\
\hline
\end{tabular}

Table 8 Solution of ELD with wind farm

\begin{tabular}{lrc}
\hline Unit & Power (MW) & Operation cost (\$) \\
\hline G1 (Coal) & 94.9286 & $2,967.33$ \\
G2 (Coal) & 99.9710 & $4,125.33$ \\
G3 (Coal) & 592.0273 & $12,290.35$ \\
G4 (Gas) & 258.9938 & $5,802.31$ \\
G5 (Gas) & 110.0097 & $3,189.00$ \\
G6 (Oil) & 40.5473 & $1,083.54$ \\
G7 (Wind) & 3.8621 & $1,657.76$ \\
Total & $1,200.0000$ & $31,115.63$ \\
Overall cost (\$) & \multicolumn{2}{c}{$31,115.63$} \\
\hline
\end{tabular}

In this paper, two of most concerned GHGs emissions, $\mathrm{CO}_{2}$ and $\mathrm{NO}_{2}$ are considered in the model. The emission characteristics of the units and emission allowance price are shown in the Tables 4 and 5. The wind farm forecast system demand and output are shown in Table 6.

\subsection{Case-I. ELD model without and with wind farm}

In this case study, the system load is 1,200 MW and the system loss power is assumed to be zero. The basic ELD model with and without wind farm are tested on the system and the simulation results are shown in Tables 7,8 and Fig. 5.

It can be shown that the solution of ED with wind farm succeeds in reducing generated power and operation costs 
Table 9 Solution of CEED without wind farm

\begin{tabular}{lrcc}
\hline Unit & Power (MW) & Operation cost (\$) & Emission cost (\$) \\
\hline G1 (Coal) & 95.5408 & $2,986.10$ & $3,202.99$ \\
G2 (Coal) & 20.7747 & $2,820.83$ & $3,029.61$ \\
G3 (Coal) & 598.7496 & $12,414.63$ & $8,641.41$ \\
G4 (Gas) & 509.7226 & $10,924.30$ & 852.97 \\
G5 (Gas) & 333.1363 & $7,978.45$ & 590.56 \\
G6 (Oil) & 42.0759 & $1,131.62$ & 495.65 \\
Total & $1,600.0000$ & $38,255.93$ & $16,813.19$ \\
Overall cost (\$) & & $55,069.12$ & \\
\hline
\end{tabular}

Table 10 Solution of CEED with wind farm

\begin{tabular}{lrcc}
\hline Unit & Power (MW) & Operation cost (\$) & Emission cost (\$) \\
\hline G1 (Coal) & 95.3455 & $2,980.80$ & $3,200.81$ \\
G2 (Coal) & 21.3548 & $2,835.68$ & $3,039.05$ \\
G3 (Coal) & 569.0520 & $11,708.60$ & $8,404.66$ \\
G4 (Gas) & 507.6528 & $10,885.02$ & 849.54 \\
G5 (Gas) & 296.0316 & $7,159.18$ & 530.05 \\
G6 (Oil) & 40.0636 & $1,068.30$ & 474.47 \\
G7 (Wind) & 70.4998 & $3,230.97$ & 0.00 \\
Total & $1,600.0000$ & $39,868.55$ & $16,498.57$ \\
Overall cost (\$) & & $56,367.12$ & \\
\hline
\end{tabular}

of some fuel units (G1, G3, G4, G5). However, the outputs and scheduling costs of generators (G2, G6) were increased slightly. The reason is that although wind power generators have lots of advantages, the operation cost caused by wind prediction errors is really expensive. With the wind power generator, part of the load of high cost units (G1, G3, G4, G5) is shifted to comparative low cost units (G2, G6). The operation cost of solution of ED with wind farm is highly increased in comparison with solution of ED without wind farm. In addition, the wind power government subsidy is just a little bit due to the low wind power output.

The generated wind power in this case is $3.8621 \mathrm{MW}$ which is far less than the predicted wind power (45 MW), and the cost incurred by overestimation will be applied. The operator needs to purchase more power from another source. Furthermore, the common ED model does not take in account the emission issue. The incorporation of wind power in simple ED problem is not an economic solution due to the really high operation cost of wind power.

\subsection{Case-II. CEED model without and with wind farm}

In this case study, the system load is 1,600 MW and the system loss power is assumed to be zero. The CEED model with and without wind farm are performed on the test system and the simulation results are shown in Tables 9, 10 and Fig. 6.

The system load is increased to $1,600 \mathrm{MW}$ in this case. But the load is still less than the maximum capacity for
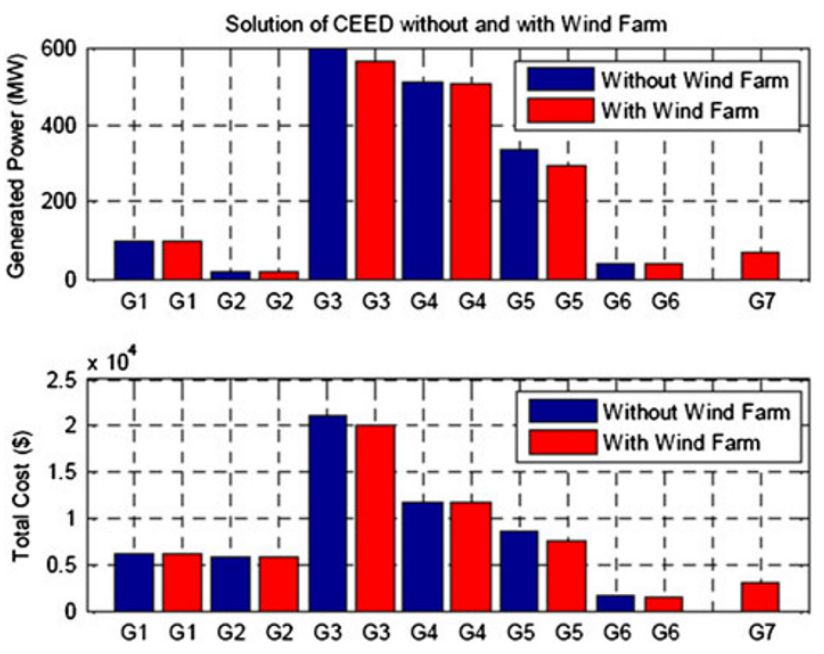

Fig. 6 Solutions of CEED models without and with wind farm

both thermal units and system with wind power. The objective of CEED is to minimize the total system operation costs and greenhouse gases $\left(\mathrm{CO}_{2}\right.$ and $\left.\mathrm{NO}_{2}\right)$ emission costs. It is clear that part of the load of highly polluted fuel fired units $(\mathrm{G} 1 \sim \mathrm{G} 6)$ is shifted to no emission polluted wind power generator (G7). Although the wind power cost is expensive, emission cost were decreased in the solution of CEED with wind farm. The reason is that the government wind power subsidy is directly proportional to the output wind power. In this case, the real generated wind power is $70.4998 \mathrm{MW}$ which is larger than the predicted wind power (45 MW). The underestimation situation will be considerate and the cost for not using all wind power available from wind turbine should be applied. From Tables 9 and 10, we can find that the CEED model with wind farm reduces the emission cost dramatically in comparison with CEED solution without wind power because of the no-emission character of wind energy. In Eq. (9), the government wind power subsidy is directly proportional to the output of wind power. Thus, the overall cost is acceptable from a standpoint of wind farm operator. Therefore, the results have shown that the proposed CEED with wind energy gives a better emission solution efficiently and economically.

\subsection{Case-III. Comparisons with other approaches}

In order to evaluate the performance of the proposed method, GA, Immune Algorithm (IA) [37], and PSO are employed in the case studies. For comparison purposes, these algorithms are used directly to solve the CEED problem with wind power. For the proposed SQP-PSO algorithm, the population size is 100 and maximum iteration is 3 for PSO. Meanwhile, in order to make a fair comparison of the other approaches, we fixed the same 
Table 11 Comparison of different approaches

\begin{tabular}{llll}
\hline Algorithm & Best solution (\$) & $\begin{array}{l}\text { Average } \\
\text { solution }(\$)\end{array}$ & $\begin{array}{l}\text { Average } \\
\text { time }(\mathrm{s})\end{array}$ \\
\hline GA & $57,369.97$ & $57,916.20$ & 13.28 \\
IA & $57,180.98$ & $57,669.57$ & 12.57 \\
PSO & $56,714.06$ & $57,417.04$ & 8.01 \\
SQP + PSO & $56,367.12$ & $56,538.19$ & 1.29 \\
\hline
\end{tabular}

population size as 100 and tested them to reach maximum iteration 100. The initial crossover and mutation rates for GA and IA were all set as $80 \%$ and $5 \%$. All the programs were run on a $2.66 \mathrm{GHz}$, Intel Core 2, with 4G RAM desktop. Table 11 shows the results out of 50 runs with each method

A comparison with other approaches is made to evaluate the proposed algorithm which is shown in Table 11. As shown, we can conclude that, the proposed hybrid approach can greatly enhances the searching ability and ensures quality of average solutions, saves computation time, and also efficiently manages the system constraints.

\section{Conclusion}

UC and ED problem of wind power will start to affect market price of smart grid system, because it became a factor affecting the operation of smart grid and hence the cost. Wind power has impact on the smart grid, since most wind energy flows on to the transmission grid. This paper developed a hybrid method combining the SQP and PSO to achieve faster and better optimization performance. The method was successfully applied to solve the power system ED problem considering GHGs emissions and wind power in an integrated CEED model, where the valve-point effect is also taken into account. In the present work, the wind speed distribution probability functions are applied in formulating the optimization model to address the uncertainties involved. The proposed hybrid method was applied to solve the CEED problem of a test system involving 6 thermal units and 1 wind farm. The comparisons were made between the classical ED and the proposed CEED model with and without wind farm. The proposed CEED model with wind farm shows a better performance in terms of less emission cost. In addition, the resultant overall dispatching cost is also optimized considering the government subsidy. Furthermore, the proposed hybrid optimization method was compared with other optimization approaches for the studied cases. The simulation results show that the hybrid method is better in terms of the speed and accuracy. Compared to the classical PSO and other methods, it can be concluded that the hybrid method greatly enhances the searching ability and efficiently manages the system constraints, therefore providing a new and efficient tool for the CEED problem.

Open Access This article is distributed under the terms of the Creative Commons Attribution License which permits any use, distribution, and reproduction in any medium, provided the original author(s) and the source are credited.

\section{References}

[1] Zhu JZ (2009) Optimization of power system operation. WileyIEEE, Piscataway

[2] Wong KP, Wong YW (1995) Thermal generator scheduling using hybrid genetic/simulated-annealing approach. IEE Proc Gener Transm Distrib 142(4):372-380

[3] Wong KP, Wong YW (1996) Combined genetic algorithm/ simulated annealing/fuzzy set approach to short-term generation scheduling with take-or-pay fuel contract. IEEE Trans Power Syst 11(1):112-118

[4] Zhao JH, Dong ZY, Li X et al (2007) A framework for electricity price spike analysis with advanced data mining methods. IEEE Trans Power Syst 22(1):376-385

[5] Zhao JH, Wen FS, Dong ZY et al (2012) Optimal dispatch of electric vehicles and wind power using enhanced particle swarm optimization. IEEE Trans Ind Inform 8(4):889-899

[6] Gungor VC, Sahin D, Kocak T (2011) Smart grid technologies: communication technologies and standards. IEEE Trans Ind Inform 7(4):529-539

[7] Dong ZY, Wong KP, Meng K et al (2006) Wind power impact on system operations and planning. In: Proceedings of the 2010 power and energy society general meeting (PES'10), Minneapolis, 25-29 Jul 2010, p 5

[8] Patel MR (2006) Wind and solar power systems. CRC Press, Boca Raton

[9] Hetzer J, Yu DC, Bhattrarai K (2008) An economic dispatch model incorporating wind power. IEEE Trans Energy Convers 23(2):603-611

[10] Liu X, Xu W (2010) Minimum emission dispatch constrained by stochastic wind power availability and cost. IEEE Trans Power Syst 25(3):1705-1713

[11] Wong KP, Fung CC (1993) Simulated annealing based economic dispatch algorithm. IEE Proc Gener Transm Distrib 140(6):509-515

[12] Wong KP, Wong YW (1994) Genetic and genetic/simulatedannealing approaches to economic dispatch. IEE Proc Gener Transm Distrib 141(5):507-513

[13] Vlachogiannis JG, Lee KY (2008) Quantum-inspired evolutionary algorithm for real and reactive power dispatch. IEEE Trans Power Syst 23(4):1627-1636

[14] Tsai MS, Hsu FY (2010) Application of grey correlation analysis in evolutionary programming for distribution system feeder reconfiguration. IEEE Trans Power Syst 25(2):1126-1133

[15] Lin XN, Ke SH, Li ZT (2010) A fault diagnosis method of power systems based on improved objective function and genetic algorithm-tabu search. IEEE Trans Power Deliv 25(3): 1268-1274

[16] Al-Sumait JS, Al-Othman AK, Sykulski JK (2007) Application of pattern search method to power system valve-point economic load dispatch. Int J Electr Power Energy Syst 29(10):720-730

[17] Ling SH, Iu HHC, Leung FHF (2008) Improved hybrid particle swarm optimized wavelet neural network for modeling the 
development of fluid dispensing for electronic packaging. IEEE Trans Ind Electron 55(9):34-42

[18] Meng K, Wang HG, Dong ZY (2010) Quantum-inspired particle swarm optimization for valve-point economic load dispatch. IEEE Trans Power Syst 25(1):215-222

[19] Yao F, Meng K, Zhao X et al (2011) Differential evolution algorithm for multi-objective economic load dispatch considering minimum emission costs. In: Proceedings of the 2011 IEEE power and energy society general meeting, Detroit, 24-28 Jul 2011, p 5

[20] Duvvuru N, Swarup KS (2011) A hybrid interior point assisted differential evolution algorithm for economic dispatch. IEEE Trans Power Syst 26(1):541-549

[21] Attaviriyanupap P, Kita H, Tanaka E et al (2002) A hybrid EP and SQP for dynamic economic dispatch with non-smooth fuel cost function. IEEE Trans Power Syst 17(2):411-416

[22] Wang SK, Chiou JP, Liu CW (2007) Non-smooth/non-convex economic dispatch by a novel hybrid differential evolution algorithm. IET Gener Transm Distrib 1(5):793-803

[23] Bhattacharya A, Cattopadhyay PK (2010) Hybrid differential evolution with biogeography based optimization for solution of economic load dispatch. IEEE Trans Power Syst 25(4):1955-1964

[24] Masters GM (2005) Renewable and efficient electric power systems. Wiley, Hoboken

[25] Carta JA, Ramirez P, Velazquez S (2009) A review of wind speed probability distributions used in wind energy analysis: case studies in the Canary Islands. Renew Sustain Energy Rev 13(5):933-955

[26] Liu X (2010) Economic load dispatch constrained by wind power availability: a wait-and-see approach. IEEE Trans Smart Grid 1(4):347-355

[27] Meng K, Wang HG, Dong ZY et al (2010) Quantum-inspired particle swarm optimization for valve-point economic load dispatch. IEEE Trans Power Syst 25(1):215-222

[28] Olsson AE (2011) Particle swarm optimization: theory, techniques and applications. Nova Science, New York

[29] Office of Gas and Electricity Markets (Ofgem) (2012) Annual report and accounts 2011-12 (For the year ended 31 March 2012), The Stationery Office, London

[30] Boggs PT, Tolle JW (1996) Sequential quadratic programming. Acta Numer 4:1-52

[31] Hanan SP (1975) A globally convergent method for nonlinear programming. J Optim Theory Appl 22(3):297-309

[32] Powell MJD (1978) A fast algorithm for nonlinearly constrained optimization calculations. In: Watson GA (ed) Numerical analysis, Lecture notes in Mathematics, vol 630. Springer, Berlin, pp 144-157

[33] Kennedy J, Eberhart R (1995) Particle swarm optimization. In: Proceedings of the IEEE international conference on neural networks (ICNN'95), vol 4, Perth, 27 Nov-1 Dec 1995, pp 1942-1948

[34] Duvvuru N, Swarup KS (2011) A hybrid interior point assisted differential evolution algorithm for economic dispatch. IEEE Trans Power Syst 26(2):541-549

[35] Venkatesh P, Lee KY (2008) Multi-objective evolutionary programming for economic emission dispatch problem. In: Proceedings of the 2008 IEEE power and energy society general meeting-conversion and delivery of electrical energy in the 21st century, Pittsburgh, 20-24 Jul 2008, p 8

[36] Australian Bureau of Meteorology. http://www.bom.gov.au. Accessed 2012

[37] Farmer JD, Packard N, Perelson A (1986) The immune system, adaptation and machine learning. Phys D Arch 2(1-3):187-204

[38] Yao F, Dong ZY, Meng K et al (2012) Quantum-inspired particle swarm optimization for power system operations considering wind power uncertainty and carbon tax in Australia. IEEE Trans Ind Inform 8(4):880-888

\section{Author Biographies}

Yang ZHANG is working towards the Ph.D. degree at the School of Electrical, Electronics and Computer Engineering, University of Western Australia, Perth, Australia. His research interests are power generation and operation optimization of sustainable energy system and smart grid, energy storage.

Fang YAO (S'09) received the Ph.D. degree in Electrical Engineering from the University of Western Australia, Perth, Australia, in 2012. He is with Schneider Electric, Beijing, China. His research interests are wind power generation and optimization of sustainable energy system.

Herbert HO-CHING IU received the B.Eng. (Hons.) degree in Electrical and Electronic Engineering from the University of Hong Kong, Hong Kong, in 1997, and the Ph.D. degree from the Hong Kong Polytechnic University, Hong Kong, in 2000. Since 2002, he has been with the School of Electrical, Electronic and Computer Engineering, University of Western Australia, Perth, Australia, where he was initially a Lecturer and is currently a Professor. He was a Visiting Lecturer with the University of Reims Champagne-Ardenne, Reims, France, in 2004, and a Visiting Assistant Professor with the Hong Kong Polytechnic University in 2006. He is the author of more than 100 published papers. He currently serves as an Associate Editor for International Journal of Circuit Theory and Applications, IEEE Circuits and Systems Society Newsletter, and International Journal of Bifurcation and Chaos, an Editorial Board Member for Australian Journal of Electrical and Electronics Engineering. He is a Co-editor of Control of Chaos in Nonlinear Circuits and Systems (World Scientific, 2009). His research interests include power electronics, renewable energy, smart grid, nonlinear dynamics, current sensing techniques, and memristive systems.

Tyrone FERNANDO received the B.Eng. (Hons.) and Ph.D. degrees in Electrical and Electronic Engineering, all from The University of Melbourne, Australia, in 1990 and 1997, respectively. He joined the University of Western Australia in 1996 where he is currently a Professor. He was the Associate Head and Deputy Head in the School of Electrical, Electronic, and Computer Engineering at the University of Western Australia in 2008-2010, respectively. His current research activities are in the areas of systems and control theory and application of control theory to biomedical systems.

Kit PO WONG received the M.Sc., Ph.D., and higher doctorate D.Eng. degrees from the University of Manchester, Institute of Science and Technology, Manchester, UK, in 1972, 1974, and 2001, respectively. He is a Fellow of IEEE. Since 1974, he has been with the School of Electrical, Electronic and Computer Engineering, The University of Western Australia, where he is currently a Winthrop Professor. His current research interests include power system analysis, planning and operations, and smart grids. Prof. Wong received three Sir John Madsen Medals (1981, 1982, and 1988) from the Institution of Engineers Australia, the 1999 Outstanding Engineer Award from IEEE Power Chapter Western Australia, and the 2000 IEEE Third Millennium Award. He was General Chairman of IEEE/ CSEE PowerCon 2000 conference. He was an Editor-in-Chief of IEE Proceedings in Generation, Transmission and Distribution. Currently he is serving as Editor-in-Chief for IEEE Power Engineering Letters of the IEEE PES Transactions. 